\title{
PENINGKATAN KOMPETENSI GURU BK MELALUI KOMUNITAS MGBK
}

\author{
Abdoel Muis \\ SMK Negeri 4 Jember \\ abdoel.muis@gmail.com
}

\begin{abstract}
Abstrak
Undang-undang Nomor 20 Tahun 2003 tentang Sistem pendidikan Nasional pasal 1 ayat 6 menyebutkan secara rinci tentang profesi pendidik. Beberapa diantaranya adalah guru, dosen, konselor, pamong belajar, widyaiswara. Disebutkan pula bahwa tutor, instruktur, ataupun fasilitator juga merupakan seorang pendidik. Guru bimbingan dan konseling (BK) sebagai seorang pendidik diharapkan mampu menjalankan tugasnya secara profesional dan menguasai kompetensi sesuai dengan standar dari pemerintah. Wujud nyata guru BK profesional adalah kemampuan untuk menjalankan tugas pokok dan fungsi Bimbingan dan Konseling di sekolah yang meliputi 17 aspek kompetensi sesuai dengan Permendiknas RI Nomor 27 tahun 2008 tentang Standar Kualifikasi Akademik dan Kompetensi Konselor. Diperlukan wadah organisasi profesi untuk menunjang peningkatan kompetensi ini, salah satunya adalah melalui Komunitas MGBK (Musyawarah Guru Bimbingan dan Konseling).
\end{abstract}

Kata Kunci: Kompetensi , Musyawarah Guru Bimbingan dan Konseling

\begin{abstract}
Law Number 20 of 2003 concerning the National Education System Article 1 paragraph 6 mentions in detail the teaching profession. Some of them are teachers, lecturers, counselors, tutors, widyaiswara. It was also stated that the tutor, instructor, or facilitator is also an educator. Guidance and counseling teachers (BK) as educators are expected to be able to carry out their duties professionally and master competencies in accordance with government standards. The real form of professional guidance and counseling teachers is the ability to carry out the main tasks and functions of Guidance and Counseling in schools which include 17 aspects of competence in accordance with the Minister of National Education Regulation Number 27 of 2008 concerning Academic Qualification Standards and Counselor Competencies. A professional organization forum is needed to support this competency improvement, one of which is through the MGBK Community (Guidance and Counseling Teacher Deliberation).
\end{abstract}

Keywords: Competence, Guidance and Counseling Teacher Deliberation

\section{PENDAHULUAN}

Pendidikan merupakan usaha dengan sadar dan terencana yang didesain sedemikian rupa demi pencapaian tujuan yang ditetapkan. Kualitas pendidikan menjadi salah satu hal yang utama. Salah satu penentu kualitas pendidikan terbaik adalah adanya tenaga pendidik/guru yang kompeten. Sejak diberlakukannya Undang-undang Nomor 14 tahun 2005, seorang guru dihadapkan pada kewajiban bertindak dan bersikap profesional. Standar yang termaktub dalam undang-undang harus terpenuhi. Sebagai agen terdepan pelaksanaan pendidikan, kualitas dan kapabilitas seorang guru menjadi pertaruhan. Guru membutuhkan wadah untuk mendukung dan mengontrol kompetensi dan kualitasnya, salah satunya melalui wadah organisasi profesi di bawah naungan dinas pendidikan yaitu Musyawarah Guru Bidang Studi/Mata Pelajaran atau bagi guru Bimbingan dan Konseling dikenal dengan istilah Komunitas MGBK (Musyawarah Guru Bimbingan dan Konseling). Paradigma pendidikan senantiasa berubah. Kurikulum menyesuaikan dengan tuntutan zaman sehingga pelaksanaan layanan BK disekolah memerlukan ketepatan dalam memilih strategi atau metode pelayanan. Peran Komunitas MGBK sangat penting mengingat organisasi ini dalam setiap pertemuan membahas substansi materi BK baik secara teoritis maupun praktis. Permasalahan yang ditemui di lapangan di kupas tuntas dan penemuan atau inovasi terbaru dalam bidang bimbingan dan konseling disebarluaskan. MGBK menjadi ajang untuk meningkatkan kemampuan dan performa kinerja guru BK sehingga tuntutan profesionalitas akan terpenuhi. Tujuan penulis membuat penelitian ini adalah untuk menunjukan efektivitas peningkatan kompetensi guru.

\section{PEMBAHASAN}

\section{Kompetensi Guru Bimbingan dan Konseling}

Bimbingan dan Konseling merupakan bagian integral pendidikan di sekolah yang memberikan pelayanan bantuan kepada peserta didik secara individual maupun kelompok agar mampu berkembang optimal dan mandiri sesuai aturan/norma yang berlaku (Saidah dalam Winarno, 2013). Diperlukan tenaga ahli yang telah memiliki 
kualifikasi kompetensi standar seorang konselor/guru Bimbingan dan Konseling.

Kompetensi merupakan seperangkat tindakan penuh tanggungjawab yang dimiliki seseorang sebagai syarat untuk dianggap mampu dalam pelaksanaaan tugas dalam bidang pekerjaan. Kompetensi ditunjukkan dengan kemahiran, ketepatan, serta keberhasilan bertindak (Majid, 2006).

Menurut Masruroh (2009) Kompetensi lebih kepada pengetahuan, keterampilan dan perilaku yang harus dimiliki, dihayati, dikuasai lalu diaktualisasikan dalam melaksanakan tugas profesional. Guru BK adalah seorang pendidik yang memiliki kualifikasi akademik minimal Sarjana (S-1) bidang Bimbingan dan Konseling dan juga memiliki kompetensi bidang Bimbingan Konseling, sedangkan Konselor merupakan seorang pendidik profesional dengan kualifikasi akademik minimal S-1 Bimbingan dan Konseling dan telah lulus Pendidikan Profesi Konselor (PPK).

Permendiknas No 27 Tahun 2018 yang membahas Standar Kualifikasi Akademik dan Kompetensi Konselor merumuskan standar kompetensi konteks tugas guru BK kedalam empat kompetensi utama, yakni kompetensi pedagogik, kepribaddian, sosial dan professional. Secara rinci, empat kompetensi inti ini dipecah ke dalam 17 aspek.

Kompetensi pedagogik memuat tiga aspek yaitu penguasaan teori dan praksis pendidikan, kemampuan pengaplikasian perkembangan fisiologis dan psikologis serta perilaku peserta didik dan penguasaan esensi pelayanan BK dalam jalur, jenis dan jenjang satuan pendidikan. Kompetensi kepribadian terdiri atas aspekKeimanandan ketaqwaan kepada Tuhan Yang Maha Esa, kemampuan untuk menghargai dan menjunjung tingi nilai-nilai kemanusiaan, individualitas dan kebebasan memilih, memiliki integritas dan stabilitas kepribadian yang kuat serta mampu menampilkan kinerja berkualitas tinggi.

Kompetensi ketiga adalah kompetensi Sosial. Indikator pada aspek kompetensi ini adalah kemampuan mengimplementasikan kolaborasi intern di tempat bekerja, berperan aktif dalam organisasi dan kegiatan profesi BK serta mampu mengimplementasikan kolaborasi antar profesi. Kompetensi terakhir berupa kompetensi professional ditandai dengan penguasaan konsep dan praksis asesmen untuk memahami kondisi, kebutuhan dan masalah konseli, penguasaan kerangka teoretik dan praksis BK, mampu merancang program BK, mampu mengimplementasikan program BK yang komprehensif, memiliki kemampuan menilai proses dan hasil kegiatan BK, memiliki kesadaran dan komitmen terhadap etika profesional dan juga memiliki penguasaan terhadap konsep dan praksis penelitian dalam bidang Bimbingan dan Konseling.

\section{Komunitas MGBK (Musyawarah Guru Bimbingan dan Konseling)}

Komunitas atau kelompok Musyawarah Guru Mata Pelajaran/Bidang Studi merupakan suatu wadah perkumpulan guru mata pelajaran di suatu sanggar, Kabupaten/Kota dan berfungsi sebagai sarana untuk berkomunikasi, belajar, bertukar pikiran dan berbagi pengalaman dalam upaya meningkatkan kinerja guru sebagai pelaku perubahan reorientasi pembelajaran di kelas (Winarno, 2013). Sedangkan Komunitas MGBK (Musyawarah Guru Bimbingan dan Konseling) merupakan organisasi atau wadah kegiatan profesional para guru BK pada SMP/MTs sampai SMA/SMK/MA yang berada dalam satu wilayah Kabupaten/Kota (Sulistyowati, 2018).

Winarno (2013) menjelaskan tujuan MGMP adalah mengembangkan kreativitas, inovasi, profesionalisme para guru serta memperluas wawasan serta pengetahuan mereka. Guru mata pelajaran/guru pembimbing akan belajar bagaimana mewujudkan proses belajar mengajar yang efektif, dan mengembangkan budaya kelas yang kondusif untuk belajar berupa suasana yang membuat peserta didi merasa senang, asyik dan mampu mencerdaskan siswa.

Menurut Sulistyowati (2018), MGBK harus memiliki pedoman/standar pengembangan organisasi. Standar Pengembangan yang harus dipenuhi oleh MGBK meliputi standar organisasi, standar program, standar pengelolaan, standar sarana dan prasarana, standar sumber daya manusia (SDM), standar pembiayaan, dan juga standar penjaminan mutu.

\section{Standar program}

Setiap komunitas MGBK menyusun program di awal kegiatan. Setiap program hendaknya mengacu pada 3 hal berikut:

1. Penyusunan program MGBK.

Program BK minimal berisi visi, misi , tujuan, dan matrik/kalenderer kegiatan.

2. Program MGBK diketahui oleh Ketua MKKS (Musyawarah Kerja Kepala Sekolah) dan disyahkan oleh Kepala Dinas Pendidikan Kabupaten/Kota.

3. Program MGBK terdiri atas program rutin dan program pengembangan.

Program rutin yang dicanangkan komunitas hendaknya mencakup kegiatan diskusi permasalahan pembelajaran atau BK, penyusunan program BK, analisis kurikulum terbaru. penyusunan instrumen evaluasi, pembahasan kesiapan menghadapi Ujian Nasional.

Komunitas MGBK dapat memilih program pengembangan yang diiinginkan. Setidaknya 3 kegiatan yang perlu dilaksanakan. Pilihan kegiatan tersebut adalah tentang penelitian, penulisan Karya Tulis Ilmiah, kegatan 
Semiloka dan diskusi panel, diklat berjenjang, penerbitan jurnal MGBK, pembuatan website MGBK, mengikuti Forum MGBK provinsi dan peningkatan kompetisi kinerja guru. Selain itu jenis pengembangan lain yang bisa dipilih seperti Peer Coaching, Lesson Study, Professional Learning Community, Global Gateway.

\section{Standar Organisasi}

Menurut Sulistyowati (2018), diharapkan standar organisasi komunitas MGBK memenuhi hal berikut:

1. Komunitas MGBK terdiri atas pengurus, anggota, adanya SK pengesahan oleh Dinas Pendidikan Kabupaten/Kota, dan memiliki Anggaran Dasar/Anggaran Rumah Tangga.

2. Jajaran pengurus MGBK terdiri dari Ketua, Sekretaris, Bendahara, dan Bidang, dipilih oleh anggota sesuai dengan AD/ART

3. Anggota komunitas MGBK terdiri atas guru BK di jenjang SMP/MTs, SMA/MA, SMK/MAK, SLB/MALB.

\section{Standar pengelolaan}

Pengelolaan komunitas MGBK diharapakan dapat mengacu pada hal berikut:

1. Pengelolaan keseluruhan program menjadi tanggung jawab ketua MGBK.

2. Pelaksanaan setiap program dilakukan oleh panitia yang dipimpin oleh seorang penanggung jawab berdasarkan surat keputusan ketua MGBK

3. Pelaksanaan setiap program berpedoman pada Kerangka Acuan Kerja yang disusun oleh pengurus.

4. Pada setiap kegiatan maka panitia akan menyusun proposal kegiatan yang meliputi detail perencanaan, pelaksanaan, pembiayaan, dan pelaporan pada akhir kegiatan.

5. Pengurus berkewajiban untuk memantau dan mengevaluasi kegiatan.

\section{Standar Sumber Daya Manusia}

Sumber Daya Manusia (SDM) sangat mempengaruhi berhasilnya suatu organisasi. Standar Sumber Daya Manusia yang seharusnya dimiliki komunitas MGBK di tiap Kabupaten/Kota adalah:

1. Memiliki Pembina yang berkualifikasi akademik sekurang-kurangnya S1, memiliki pengalaman mengajar sekurang-kurangnya 10 tahun, memiliki keahlian yang relevan.

2. Pembina pada butir 1 bisa merupakan salah satu dari unsur professional seperti Pengawas, Kepala Sekolah, Widyaiswara, Dosen, Instruktur, guru Inti, Pemandu/tutor, ataupun para Pejabat struktural dan non struktural di lingkup Dinas Pendidikan Propinsi dan Kabupaten/Kota.

\section{Standar Sarana Prasarana}

Sarana akan mendukung keberhasilan dan kelancarana dalam berbagai kegiatan. Pada setiap komunitas MGBK diharapkan sarana dan prasarana mengacu pada adanya ruang/gedung untuk kegiatan MGBK, terdapat inventaris Komputer, adanya contoh media pembelajaran, memiliki sarana resentasi seperti OHP/LCD Proyektor, terdapat alat untuk saluran komunikasi seperti Telepon dan Faximile. Adapun Sarana dan prasarana tambahan bisa berupa Laboratorium, Perpustakaan, media Audio Visual Aids, Handy Cam dan atau kamera digital, tersedianya jaringan Internet yang stabil dan Davinet (Digital Audio Visual Network).

\section{Standar Pembiayaan}

Standar pembiayaan komunitas MGBK terdiri atas alur dana MGBK, sumber dana dan kegunaan dana. Pembiayaan kegiatan MGBK akan dilaksanakan dengan mencakup sumber dana, penggunaan, dan pertanggungjawaban. Sumber utama dana komunitas MGBK adalah dari iuran Iuran anggota, Dinas Pendidikan, Departemen, Donatur, Unit produksi, Hasil kerjasama/sponshorship dan Masyarakat. Dana yang dimiliki komunitas MGBK boleh dipergunakan untuk pelaksanaan program rutin, program pengembangan dan akan dipertanggungjawaban melalui pelaporan keuangan sesuai dengan ketentuan yang berlaku.

\section{Standar Penjaminan Mutu}

Penjaminan mutu dibutuhkan untuk menjamin sebuah organisasi berjalan dengan seharusya. Unsur yang dilihat pada standar ini adalah kesesuaian antara setiap standar dengan pemenuhannya, data mutu melalui pemantauan dan evaluasi. Proses penjaminan mutu komunitas MGBK diatur dalam Anggaran Rumah Tangga (ART). Setiap laporan yang ada pada komunitas MGBK meliputi substansi kegiatan dan administrasi disampaikan kepada ketua MGBK, dilanjutkan kepada ketua MKKS, dan dilanjutkan Kepala Dinas Pendidikan Kabupaten/Kota untuk mendapatkan pengesahan.

\section{Peningkatan Kompetensi Guru Bimbingan dan Konseling melalui MGBK}

Menurut Koeswara dan Halimah (2008) pengembangan profesi dapat dilakukan dengan melalui Kegiatan penataran atau kursus, Pengembangan secara mandiri/Self Development, Kegiatan yang bersifat Ilmiah, Pendekatan terapan, dan berbagai kegiatan lainnya.

Setelah seorang sarjana bekerja menjadi guru di sebuah lembaga maka peningkatan kompetensi diperoleh melalui pembinaan dari Kepala sekolah, pengawas, Kepala Dinas dan rekan sejawat tempat guru bekerja. Selanjutnya peningkatan kompetensi bisa dilakukan secara mandiri dengan melakukan kegiatan telaah kepustakaan yang 
relevan dan terbaru, pemanfaatan media, atau kolaborasi dengan narasumber yang kompeten. Seorang guru juga bisa melakukan peningkatan kompetensi dengan mengikuti kegiatan ilmiah seperti aktif dalam forum ilmiah, seminar, lokakarya, kongres, konvensi.

Dalam pelaksanaan Musyawarah Guru Bimbingan dan Konseling, peningkatan kompetensi bisa dilakukan dengan pendekatan terapan secara metodis praktis dengan saling tukar informasi, berbagi pengetahuan praksis konseling bersama rekan sejawat, melakukan pengembangan media $\mathrm{BK}$, pengembangan modul layanan, pengembangan kemampuan komunikasi konseling dan berbagai topik terkait pelayanan Bimbingan dan Konseling di Satuan Pendidikan.

Berikut adalah kegiatan yang memungkinkan untuk dikembangkan dalam Komunitas BK (Musyawarah Guru Bimbingan dan Konseling) dalam rangka meningkatkan taraf kompetensi anggotanya:

a. Peningkatan Kompetensi Pedagogik

Pelatihan/workshop tentang penguasaan landasan teoritik dalam layanan BK di sekolah, diskusi perencanaan layanan peminatan dan perencanaan individual, Pelayanan studi lanjut dan karier, isu terkini dalam dunia pendidikan terkait perkembangan peserta didik.

b. Peningkatan Kompetensi Kepribadian

Pelatihan tentang Keterampilan dasar komunikasi konseling, Public speaking, membahas contoh studi kasus, pembahasan kasus/peristiwa psikologis yang sedang in/aktual, tukar informasi penanganan kasus di sekolah.

c. Peningkatan Kompetensi Sosial

Peningkatan pemahaman kode etik ABKIN terbaru, sharing informasi terkait kerjasama dengan pihak luar, pendaftaran kolektif anggota ABKIN, mengadakan studi tiru ke MGBK lain, Meningkatkan kerjasama dan jiwa kepemimpinan melalui outbond.

d. Peningkatan Kompetensi Profesional

Mengadakan pelatihan penyusunan asesmen/instrumen pengukuran psikologis, bedah Panduan Operasional Penyelenggaraan BK dan Peraturan Menteri terkait pelayanan Bimbingan dan Konseling, Melaksanakan diskusi-brain strorming terkait analisis SWOT dalam penyusunan program BK, berlatih menyusun evaluasi, pelaporan dan tindak lanjut Bimbingan dan Konseling, Inovasi Pelayanan, Penggunaan IT dalam layanan BK, berlatih menyusun format BK dan Rencana Pelaksanaan Layanan, Mengadakan pelatihan karya tulis ilmiah, membuat Penelitian Tindakan Kelas Bimbingan dan Konseling (PTBK) serta mempublikasikannya.

Peneliti menggunakan tipe penelitian ini agar peneliti dapat memperoleh pemahaman dan dapat mendeskripsikan hubungan persepsi orang tua dengan anaknya mengenai pemilihan jurusan di SMA/SMK. Proses hubungan ini di ambil melalui kuisioner sebagai sumber utama yang digunakan peneliti untuk diinterpretasikan menjadi data penelitian.

Populasi penelitian ini adalah siswa SMPN 1 Balongbendo Sidoarjo yang berjumlah 309 siswa kelas VIII dari 9 kelas. Penentuan besar sampel penelitian menggunakan teknik Accidental Sampling sehingga didapat sampel dari kelas VIII B sebanyak 35 siswa.

Teknik analisis data menggunakan metode deskriptif korelasional. Menurut Suharsimi[4]"Penelitian deskriptif adalah penelitian yang dimaksudkan untuk menyelidiki keadaan, kondisi atau hal-hal lain yang sudah disebutkan, yang hasilnya dipaparkan dalam bentuk laporan penelitian". Menurut Agus[5]'Korelasi merupakan suatu hubungan antara satu variabel dengan variabel lainnya". Seluruh data yang digunakan dalam penelitian ini dilaksanakan pada 3 maret 2020.

\section{PENUTUP}

\section{Simpulan}

Komunitas MGBK (Musyawarah Guru Bimbingan dan Konseling) sangat dibutuhkan sebagai sarana untuk menempa dan meningkatan kompetensi para Guru BK. Kegiatan MGBK berupa peningkatan pengetahuan dan penguasaan keterampilan terkait bagaimana melaksanakan layanan bimbingan dan konseling. Organisasi profesi guru BK dalam hal ini adalah komunitas MGBK yang dikelola secara profesional akan memberikan kontibusi dan dampak positif pada peningkatan kompetensi pedagogik, sosial, kepribadian dan profesional. MGBK juga efektif sebagai media mengimbaskan ilmu yang diterima melalui jalur diseminasi.

\section{DAFTAR PUSTAKA}

Koswara, d. Deni \& Halimah. 2008. Seluk-Beluk Profesi Guru. Bandung: Pribumi Mekar.

Majid, Abdul. 2006. Perencanaan Pembelajaran. Bandung: Remaja Rosda Karya.

Masuroh, Siti. 2009. Kompetensi Guru. Tersedia online di http://sitimasruroh.blogspot.com.

Permendiknas Nomor 27 Tahun 2018 tentang Standar Kualifikasi Akademik dan Kompetensi Konselor.

Sulistyowati, M.D.R. 2018. Pengelolaan MGBK dalam Meningkatkan profesionalisme Guru Bimbingan

dan Konseling SMA/MA. Jurnal Media Managemen Pendidikan Volume 1 No. 2 Oktober 2018.

Undang-undang No 20 Tahun 2003 tentang Sistem pendidikan Nasional.

Winarno, A \& Prihartini, N. 2013. Peranan Musyawarah Guru Pembimbing (MGP) dalam Meningkatkan 
Jurnal Bikotetik (Bimbingan dan Konseling : Teori dan Praktik) Volume 04 Nomor 02 Tahun 2020, 50-54

Kompetensi Guru Pembimbing SMP Kbupaten Boyolali. Jurnal Penelitian Humaniora, Vol 14, No 1, Februari 2012, hal 71-84. 